\title{
Botulinum Toxin for Pain
}

\author{
Roberto Casale ${ }^{1}$ and Valeria Tugnoli ${ }^{2}$ \\ 1 Department of Clinical Neurophysiology and Pain Rehabilitation Unit, Foundation Salvatore \\ Maugeri, IRCCS, Scientific Institute of Montescano, Montescano (PV), Italy \\ 2 Department of Clinical Neuroscience, S. Anna University Hospital of Ferrara, Ferrara, Italy
}

\section{Contents}

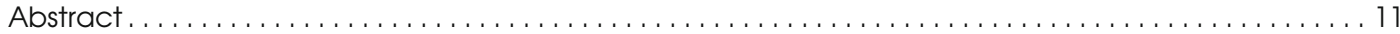

1. Impact of Botulinum Toxin (BTX) on Cholinergic Transmission $\ldots \ldots \ldots \ldots \ldots \ldots \ldots \ldots \ldots$

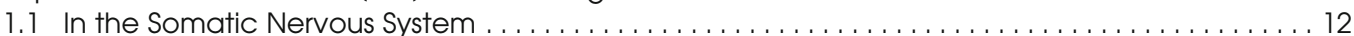

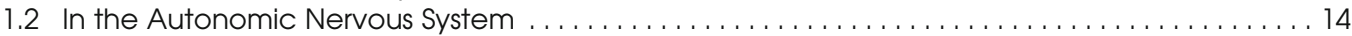

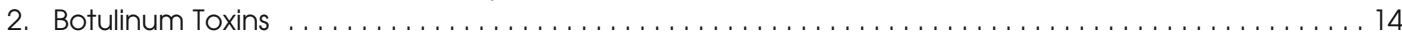

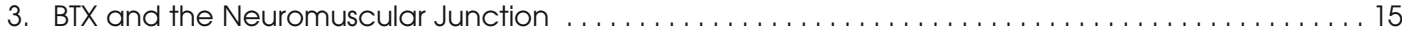

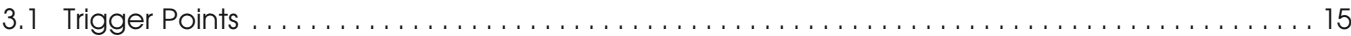

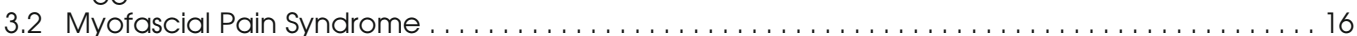

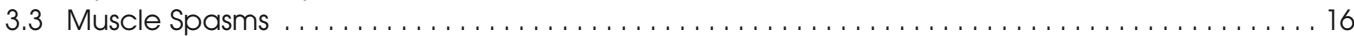

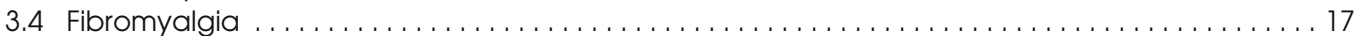

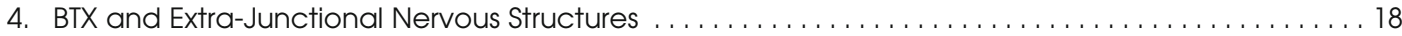

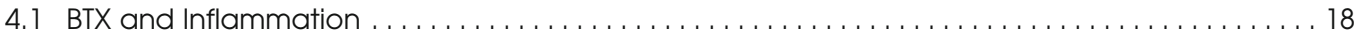

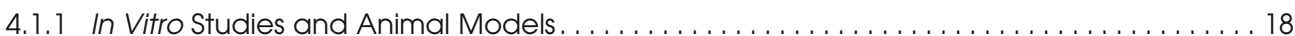

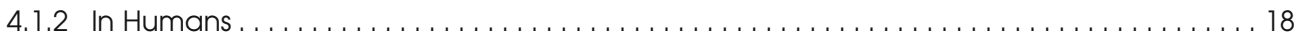

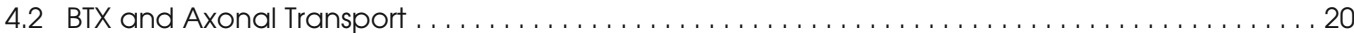

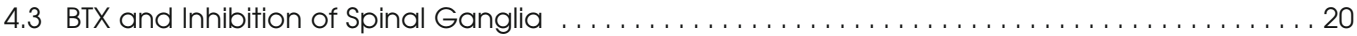

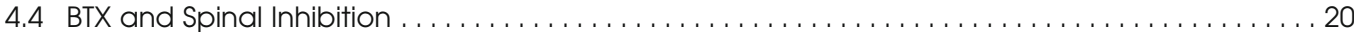

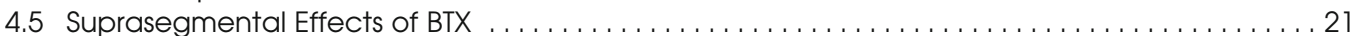

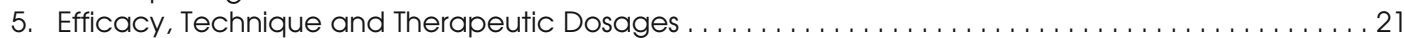

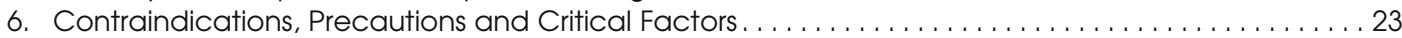

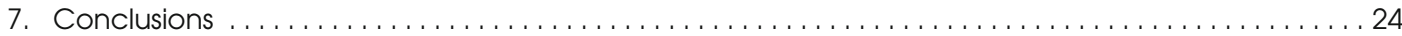

\section{Abstract}

Botulinum toxin (BTX) injection is being increasingly used 'off label' in the management of chronic pain. Data support the hypothesis of a direct analgesic effect of BTX, different to that exerted on muscle. Although the pain-reducing effect of BTX is mainly due to its ability to block acetylcholine release at the synapse, other effects on the nervous system are also thought to be involved. BTX affects cholinergic transmission in both the somatic and the autonomic nervous systems. Proposed mechanisms of action of BTX for pain relief of trigger points, muscular spasms, fibromyalgia and myofascial pain include direct action on muscle and indirect effects via action at the neuromuscular junction. In vitro and in vivo data have shown that BTX has specific antinociceptive activity relating to its effects on inflammation, axonal transport, ganglion inhibition, and spinal and suprasegmental level inhibition. Our review of the mechanisms of action, efficacy, administration techniques and therapeutic dosage of BTX for the management of chronic pain in a variety of conditions shows that although muscular tone 
and movement disorders remain the most important therapeutic applications for BTX, research suggests that BTX can also provide benefits related to effects on cholinergic control of the vascular system, autonomic function, and cholinergic control of nociceptive and antinociceptive systems. Furthermore, it appears that BTX may influence the peripheral and central nervous systems. The therapeutic potential of BTX depends mainly on the ability to deliver the toxin to the target structures, cholinergic or otherwise. Evidence suggests that BTX can be administered at standard dosages in pain disorders, where the objective is alteration of muscle tone. For conditions requiring an analgesic effect, the optimal therapeutic dosage of BTX remains to be defined.

Botulinum toxin (BTX) is widely used in neurological rehabilitation. Recently, new interest has focused on the possible application of BTX in the rehabilitation of chronic pain patients, where pain is associated with various degrees of disability. ${ }^{[1-4]}$ This interest derives from early evidence of significant pain reduction in dystonia with BTX, independent of BTX myolytic action. Preliminary clinical observations have suggested that the analgesic effect of BTX has a faster onset of action than its effect on muscle tone ${ }^{[5,6]}$ and is more prolonged. ${ }^{[7,8]}$ Use of BTX in the treatment of muscular pain associated with increased muscular tone has increased significantly and there are now considerable data to support the hypothesis of a direct analgesic effect of BTX, different to and independent from its effect on muscle tone. ${ }^{[9]}$

This article reviews the 'off-label' use of BTX in pain management in a variety of conditions. We will discuss aspects of cholinergic transmission - in particular, aspects related to and possible mechanisms for BTX-induced pain relief. For general information or specific information on the use of BTX for indications other than pain control, please refer to other articles, reviews and systemic reviews available in the literature (e.g. Cochrane Database Systemic Reviews).

\section{Impact of Botulinum Toxin (BTX) on Cholinergic Transmission}

BTX-induced inhibition of acetylcholine (ACh) release at the neuromuscular junction, between the motor nerve terminal and muscle, causes chemical denervation manifesting as a relaxation in muscle tone. When considering the precise mechanisms of action of BTX, although it is clear that the success of BTX in pain management is mainly due to its ability to block ACh synaptic release by interfering with exocytosis of cholinergic vesicles, this is not the sole effect of BTX either on the nerve endings or on the nervous system in general. In addition to the direct action of BTX on muscle and at the neuromuscular junction to reduce pain, other proposed mechanisms of pain reduction involve local neurons, the spinal cord and suprasegmental centres in the brain (figure 1), and involve both the somatic and autonomic nervous systems. These proposed BTX mechanisms of action are thought to produce effects that counter those of pain-producing noxa (harmful influences such as muscle overload, inflammation, pathology and trauma). ${ }^{[10]}$ Current data suggest that BTX is effective in pain syndromes in which increased muscle tone has generated or contributed to maintenance of the vicious circle of muscle contraction-pain-muscle contraction. ${ }^{[2,11,12]}$ However, recent research programmes investigating the analgesic and myolytic therapeutic effects of BTX have demonstrated that BTX is effective in reducing pain independent of changes in muscle tone ${ }^{[13,14]}$ because pain relief occurs prior to muscle relaxation effects or in conditions in which pain is not associated with muscle tension. ${ }^{[15,16]}$

\subsection{In the Somatic Nervous System}

As ACh is the main neurotransmitter in striated muscle, present in the neuromuscular junctions be- 


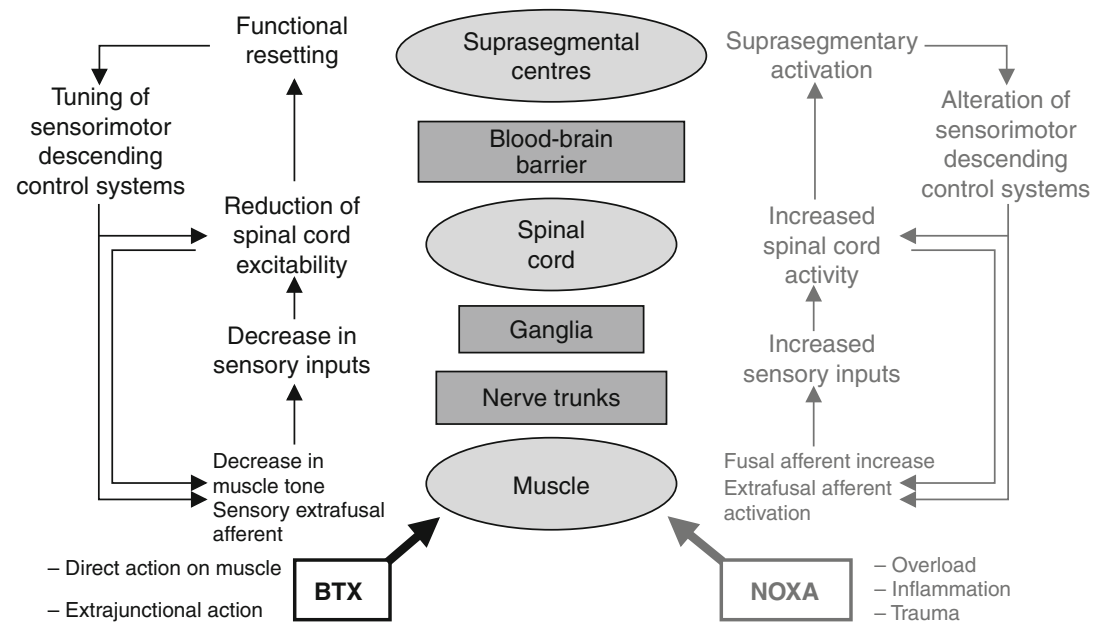

Fig. 1. Schematic diagram of possible botulinum toxin (BTX) mechanisms of action on the neuromuscular system and the corresponding effects of pain-producing noxa such as muscle overload or trauma.

tween $\alpha$-motoneurons and extrafusal muscle fibres, BTX blocks synaptic transmission of motor nerve impulses to produce direct inhibition of muscle contraction. ${ }^{[17]}$ Since ACh is also present in intrafusal muscle spindles, BTX has been shown to block neurotransmission between $\gamma$-motoneurons and in- trafusal muscle fibres. ${ }^{[17]}$ Therefore, in addition to direct blockade at the extrafusal neuromuscular junction in the muscle fibre, BTX also reduces the excitatory drive on the $\alpha$-motoneurons by reducing the intrafusal afferent signals from the muscle spindle to the spinal cord (figure 2).

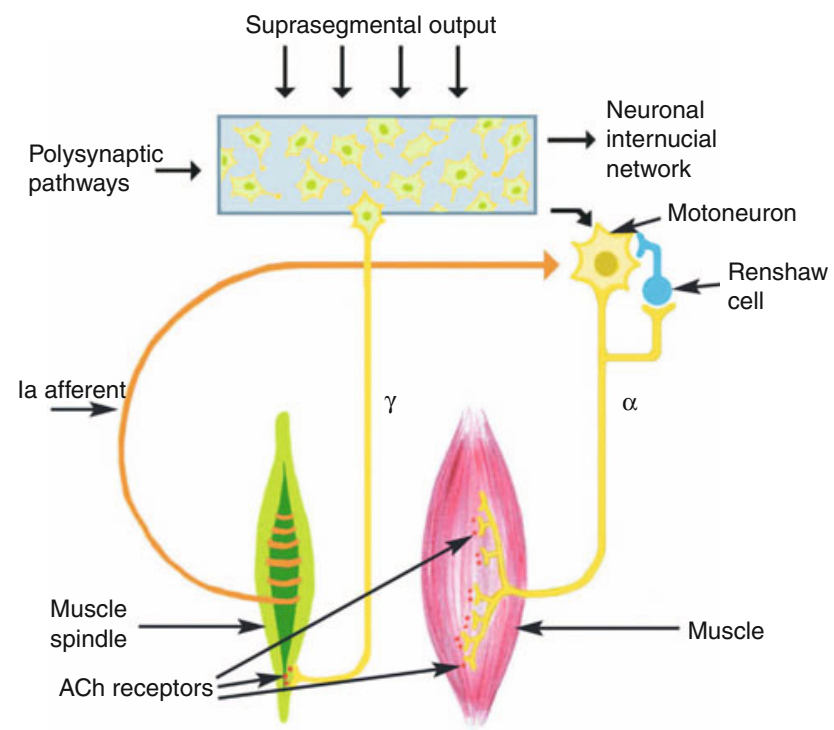

Fig. 2. Diagrammatic representation of control of muscle tone by the somatic nervous system. Both $\alpha$ - and $\gamma$-motoneurons of the extrafusal muscle fibres and intrafusal muscle spindles, respectively, have post-synaptic acetylcholine (ACh) receptors at their neuromuscular junctions and are, therefore, potential targets for botulinum toxin action. 

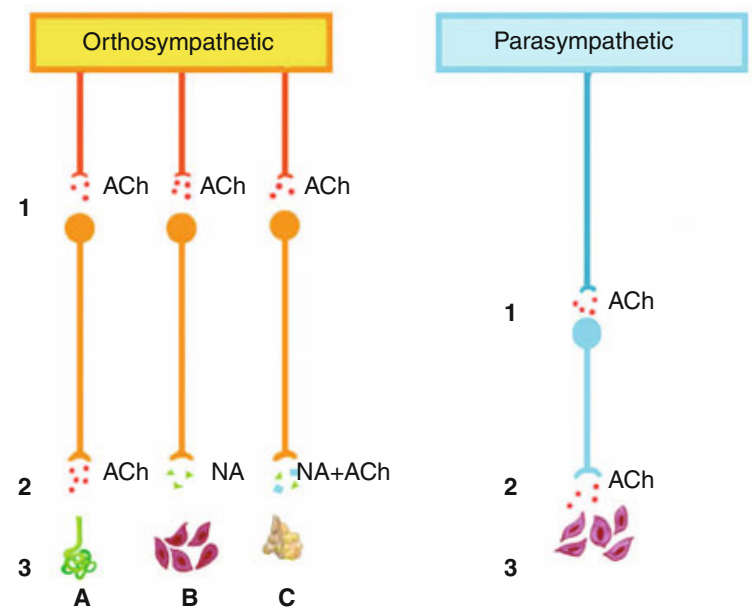

Fig. 3. The autonomic nervous system is divided into orthosympathetic (sympathetic) and parasympathetic arms. Anatomical distinction between the two arms is related to the different lengths of the post-ganglionic neurons, which are longer in the orthosympathetic than in the parasympathetic arm. In the parasympathetic arm, the ganglion is closer to the target organ (3). For both systems, acetylcholine (ACh) is the neurotransmitter at the pre-ganglionic synapses (1). ACh is the neurotransmitter at the post-ganglionic synapses in the parasympathetic arm and for orthosympathetic fibres to the eccrine sweat glands (2, A). All other post-ganglionic synapses (B) of the orthosympathetic arm are noradrenergic (NA). Both NA and ACh (NA + ACh) pathways are involved in post-ganglionic transmission at the suprarenal level (C).

\subsection{In the Autonomic Nervous System}

The autonomic nervous system is an efferent motor system that innervates the smooth muscle cells of a variety of organs. In the autonomic nervous system, the distribution and functions of cholinergic transmission are more complicated than in the somatic system other than for eccrine sweat glands; cholinergic transmission is present only at pre-ganglion level in the orthosympathetic (sensory) arm, whereas in the parasympathetic (motor) arm it is present at both pre- and post-ganglion levels (figure 3). In vascular smooth muscle cells, ACh production causes relaxation of muscle fibres and vasodilatation through nitric oxide (NO) production. However, NO is known be pro-algogenic (pain producing), being involved in the nociceptive afferent barrage, the activation pathways in vascular tissues and in the associated nervous system. ${ }^{[18]}$

In contrast, in other organs or systems (such as the gastrointestinal [GI] tract or the detrusor muscle of the bladder), ACh causes contraction of smooth muscle, as in striated muscle. ${ }^{[19]} \mathrm{ACh}$ also exerts a contraction effect on the smooth muscular cells of sweat ${ }^{[20]}$ and salivary glands. ${ }^{[21]}$

\section{Botulinum Toxins}

BTXs are composed of a family of neurotoxins (designated as serotypes A, B, C, D, E, F and G) with similar properties, all producing different degrees of flaccid muscle paralysis. Although neurotoxins of serotypes $\mathrm{A}, \mathrm{B}, \mathrm{C}$ and $\mathrm{F}$ have been clinically tested to date, ${ }^{[22]}$ only two of these are commercially available for medical use: BTX type A (BTX-A) and BTX type B (BTX-B).

SNAP-25 (synaptosome-associated protein of 25 $\mathrm{kD}$ ), which is resident in cell membranes, and VAMP (vesicle-associated membrane protein, or synaptobrevin), anchored in the vesicular membrane, are two proteins needed for binding of synaptic vesicles with the nerve endings, thereby facilitating release of ACh. In the nerve terminal, BTX-A selectively cleaves the protein SNAP-25, while BTX-B acts on VAMP. Despite their different and selective modes of action, both BTX-A and BTX-B serotypes act through a zinc-dependent mechanism via the SNARE (soluble N-ethyl-maleimide-sensitive factor-attachment protein-receptor) system. Blockade or prevention of the formation of the SNARE complex prevents the fusion of vesicles and release of neurotransmitters into the intersynaptic 
space. ${ }^{[23]}$ Therefore, SNARE complex blockade would appear to be a pivotal step in the mode of action of BTX as pain reliever. Regardless of the actual mechanism, BTX blockade of cholinergic neurotransmission can, therefore, happen not only in the neuromuscular junctions of striated and smooth muscle, but also wherever there is a cholinergic terminal and, at least theoretically, wherever neurotransmitter release is mediated through the SNARE complex, both in neurons and in other cell types. ${ }^{[24]}$

\section{BTX and the Neuromuscular Junction}

The most common indications for BTX are painful syndromes in which an increase in the muscular tone generates or maintains a vicious circle of muscle contraction-pain-muscle contraction.

The literature provides reports of many studies of BTX use in muscle-related pain, such as trigger points (TrPs), ${ }^{[25,26]}$ reflex spasms, ${ }^{[27,28]}$ contractures, ${ }^{[27,29,30]}$ fibromyalgia, myofascial syndromes, ${ }^{[31-33]}$ and pain associated with dystonia ${ }^{[11]}$ and spasticity. ${ }^{[34,35]}$ The conceptual link between these syndromes and the use of BTX is that either pain relief is secondary to a reduction in muscular tone or a decrease in muscular tone directly influences the presence of pain. In all of the abovementioned cases, the main goal of BTX treatment is a reduction in muscle tone, with pain reduction occurring as a secondary effect to local muscle flaccid paralysis.

Onset of contractures and muscular pain after an excessive and continuous effort is quite commonly reported in normal subjects. ${ }^{[36]}$ The pain is generally due to a combination of factors, such as bradykinin $(\mathrm{BKN})$ release, $\mathrm{pH}$ decrease and subsequent activation of the vanilloid (TRPV [transient receptor potential vanilloid]) receptors induced by ischaemia and the intense mechanical stimulus, and release of pain-inducing substances such as prostaglandin 2 $\left(\mathrm{PG}_{2}\right)$ and adenosine triphosphate (ATP) following mechanical membrane damage. ${ }^{[37]}$ However, in conditions such as fibromyalgia (FM) ${ }^{[38]}$ and in myofascial syndromes ${ }^{[39]}$ where BTX has considerable therapeutic use, ${ }^{[31,40-44]}$ the presence of widespread, erratic muscular pain is linked to a modest workload suggesting the involvement of central sensitization effects.

\subsection{Trigger Points}

Myofascial TrPs are hyper-irritable tender spots in the muscle or the junction of the muscle and fascia identifiable as palpable taut bands of skeletal muscle; after stimulation, they produce pain locally and in a referred pattern. Pain is mainly caused by ischaemia in the TrP area resulting in a build-up of lactic acid and potassium and stimulation of local nerve endings. Almost all skeletal muscles can have TrPs, although active TrPs are more frequently located in muscles deputed to maintain body posture, such as those in the neck, shoulders, pelvic girdle and in the chewing muscles. Particularly frequent locations can be the upper trapezius, scalene, the sternocleidomastoid, the levator scapulae and the quadratus lumborum. ${ }^{[45]}$ For each muscle, referred pain after compression of TrPs has peculiar distribution characteristics. Simons' 'motor endplate hypothesis', concerning the formation of myofascial TrPs, suggests that a muscle lesion, even when not evident, damages the extrafusal motor endplate leading to an excessive amount of ACh being released. ${ }^{[46]}$ ACh causes a local contracture (partial activation of actin and myosin) underneath the endplate via calcium ion $\left(\mathrm{Ca}^{2+}\right)$ release. In turn, the contracture, limited to the sarcomere, causes intramuscular micro-ischaemia and the release of BKN, one of the most powerful activators of the intramuscular free nerve endings and associated with deep somatic pain. This combination of factors, i.e. mechanical stimuli, prolonged ischaemia and release of pain-producing substances, is likely to cause not only the direct activation of the nociceptive pathway (as in the case of BKN), but also the activation of free nerve endings linked to Lloyd type III and type IV collagen fibres, with consequent reiteration of the vicious cycle of contractile stimulus-activation-contractile stimulus ${ }^{[47]}$ and possible development of chronic myofascial pain syndrome.

In BTX treatment of TrPs, local injections of BTX block ACh release, thus preventing continuous sarcomere contraction and breaking the cascade that 
results in peripheral activation and chronic pain. Interestingly, it is difficult to differentiate between the effects on TrPs of BTX and of TrP manipulation using the dry-needle technique ${ }^{[48]}$ or saline injection. ${ }^{[49]}$

\subsection{Myofascial Pain Syndrome}

Myofascial pain syndrome is a chronic condition affecting the fascia and characterized by TrPs, either in a single muscle or a muscle group, developing as a result of muscle injury and trauma. Although often misdiagnosed as FM, the TrPs of myofascial pain are different from the tender points of FM in that they do not follow a specified pattern. Furthermore, myofascial pain is not usually associated with the chronic fatigue and poor sleep seen in FM, and the patient may report referred pain.

Although the evidence is somewhat contradictory, clinical effectiveness for BTX in patients with myofascial syndrome has been demonstrated in several clinical studies and in anecdotal reports. ${ }^{[31,32,50,51]}$ In a small study of six patients with chronic myofascial pain syndrome, TrP injections of BTX-A significantly reduced pain in four patients. ${ }^{[31]}$ In an open-label prospective study of 77 patients with refractory myofascial syndrome, BTXA was effective in reducing pain for up to 90 days after TrP injection. ${ }^{[32]}$ In a randomized, double-blind study of patients with upper back myofascial pain syndrome, BTX-A (400 U Dysport ${ }^{\circledR}$ [Ipsen Limited, Slough, UK $]^{1}$ injected at $10 \mathrm{TrPs}$ ) significantly improved pain levels after 4-6 weeks and was well tolerated. ${ }^{[51]}$ However, in a recent systematic review of five randomized, controlled trials of BTX-A therapy in patients with myofascial syndrome, only one of the trials demonstrated that BTX-A reduced pain in these patients and the authors concluded that use of BTX-A in myofascial pain is not supported by current clinical data. ${ }^{[52]}$ However, in one of these randomized studies involving 30 patients, the BTXA dose used per injection was $50 \mathrm{U} / 0.25 \mathrm{~mL}$, a dose the authors suggest may have been too low to be effective for pain reduction, but sufficient to signifi- cantly influence the motor function of the muscle. ${ }^{[33]}$ Also, a strong placebo effect was observed, which may have masked a significant reduction in pain versus placebo with BTX-A. Lack of efficacy may also be due to the site of BTX-A injection; case reports of BTX-A injections of $15-25 \mathrm{U}$ into the middle scalene and 50-75 $\mathrm{U}$ into the levator scapula muscles have described effective pain reduction. ${ }^{[50]}$ Further studies are needed to fully investigate BTX dosage regimens, injection sites and techniques for optimum treatment of myofascial pain.

\subsection{Muscle Spasms}

Similar BTX mechanisms to those described for TrPs are implicated when there is general muscle involvement, such as in reflex spasms due to a painproducing noxa, ${ }^{[53,54]}$ and in conditions with a neurobiological basis. ${ }^{[27]}$ There are an increasing number of published reports of BTX use in neurobiological conditions, including cervical dystonia, focal dystonia, facial spasm, painful masseteric muscle hypertrophy and painful dystonia in Parkinson's disease, piriformis syndrome, scalenus anticus syndrome and pyramidal spasticity. ${ }^{[5]}$ There are also many reports describing the use and effectiveness of BTX for different types of headache and migraine. ${ }^{[55-60]}$

When muscle or related structures are involved in a painful process, the spinal cord receives an afferent barrage that can increase the discharge rate of $\alpha$ motoneurons. When the painful stimulus comes from muscle, the activation of $\alpha$-motoneurons is direct or paucisynaptic (lacking in synapses). In contrast, when the painful stimuli come from external structures, such as ligaments or joints, the afferent barrage is oligosynaptic, inducing a decrease in inhibitory stimuli and an increase in excitatory stimuli acting on interneurons at a spinal level, thus increasing the discharge rate of $\alpha$-motoneurons. ${ }^{[37]}$ In both cases, activation of $\alpha$-motoneurons results in repeated cycles of muscle contraction-pain-muscle contraction. ${ }^{[46]}$ Muscular pain also develops when the fibre structure is subjected to high torque levels,

1 The use of trade names is for product identification purposes only and does not imply endorsement. 
i.e. in the case of excessive muscular workload. In this case, pain may be caused by muscular microlesions, with release of neuropeptides as BKN, substance $\mathrm{P}$ (SP), ATP, PGs and NO, and is associated with a decrease in $\mathrm{pH}$, increased lactate and phosphate levels, compression of the intramuscular blood vessels and nerves, ischaemia (localized or not) and a reduced excitation threshold of molecular mechanoreceptors. ${ }^{[37]}$ Therefore, in addition to pain reduction due to BTX acting on the neuromuscular junction in striated muscle, BTX also reduces pain through action on the smooth muscle cells in intramuscular blood vessels, on the endplate of amyelinic nerve fibres and on inflammatory spots. These actions are discussed in detail in the section on BTX action on extra-junctional structures.

\subsection{Fibromyalgia}

Although early studies suggested that FM was a muscle disorder, recent studies indicate that the muscles are normal and that FM is a chronic pain syndrome with a central neurological basis. ${ }^{[38]} \mathrm{FM}$ is characterized by chronic fatigue, muscular fatigue and pain, allodynia, generalized hyperalgesia and poor sleep. As muscular symptoms are often associated with other symptoms, a multiaxial taxometric approach to diagnosis and treatment is required. ${ }^{[61]}$ According to the American College of Rheumatology (ACR) criteria, a person is considered to have FM if he or she has widespread pain in combination with tenderness in at least 11 of 18 specific tender point sites on digital palpitation. ${ }^{[62]}$ From a pathophysiological point of view, this clinical picture could indicate possible deficiencies in the endogenous pain-modulating mechanisms, i.e. increased central sensitization and an altered transmission of both tactile and pain afferent signals, ${ }^{[38,63]}$ in association with intrinsic muscular anomalies. ${ }^{[64,65]}$ According to several reports, an alteration of sensory and nociceptive afferent transmission exists in FM; muscles have a very low pain threshold both in tender points ${ }^{[62]}$ and in other areas. ${ }^{[66]}$ It has been demonstrated that hyperalgesia occurs not only after mechanical muscle stimulation, but can also be induced with capsaicin ${ }^{[67]}$ or hypertonic saline. ${ }^{[68]} \mathrm{A}$ functional magnetic resonance imaging study supports the hypothesis that not only afferent sensorial systems are involved in FM. ${ }^{[69]}$ In fact, diffuse noxious inhibitory controls (DNIC), part of a central pain modulatory system that relies on spinal and suprasegmental mechanisms, are also less efficient. ${ }^{[70]}$ Patients with FM also appear to display altered perception of the muscle activation needed for a given movement or to bear a weight, and they activate strategies not in agreement with Heinemann's rules describing the sequence of activation of muscle fibres according to the task. The alteration in central input appears to be linked to functional aspects that are strictly related to altered sensory perception. During voluntary contraction, this altered input undergoes many changes: it appears that the central control of muscular drive cannot 'decide on' or receives inadequate information for a correct motor choice. Although, at present, no unequivocal confirmatory data exist, a possible interpretation may emerge from amputation studies, where the sensory input is clearly altered. ${ }^{[71]}$ Sensory inputs are used at least twice - to decide what to do and how to do it - in a system defined by Wall as 'repertoire-priority', in which the motor patterns produced are as close as possible to reality. ${ }^{[72]}$ This concept fits perfectly with both the motor response to a painful stimulus and to a weight-induced muscular response. Occasionally, there are situations that have no adequate motor response in the repertoire-priority system; therefore, the altered motor and environmental output generated tends to be autoreferential, becoming chronic. In FM, overlap of altered sensory inputs - pain perception and perception of muscular load - leads to abnormal motor patterns that tend to be repeated regardless of the task. In this context, low intensity muscle contractions, even if long lasting, cause repetitive contractions and the well known erratic movement characteristics.

There is very limited clinical evidence supporting use of BTX in FM to date. ${ }^{[73-76]}$ Hypothetically, in FM, BTX should act both on the muscular front, by inhibiting the muscle contraction and ameliorating muscle metabolic conditions, ${ }^{[37]}$ as seen in TrPs and 
spasms, and extra-junctionally, via actions that are partly direct, on amyelinic fibres, and partly indirect, on the activation state of segmental and suprasegmental structures. The result should be normalization of afferent signals with a consequent functional resetting of motor strategies; however, this has not been demonstrated in clinical studies.

\section{BTX and Extra-Junctional Nervous Structures}

The analgesic potential of BTX does not appear to be due solely to its muscle relaxant effect. Evidence from in vitro and in vivo experimental models, and from the clinical setting, suggests that BTX acts on somatic and autonomic nervous pathways connected with pain perception, involving effects on neural sensory and motor endplates during neurogenic inflammation as well as effects at spinal and suprasegmental levels (figure 1).

\section{1 BTX and Inflammation}

In skeletal muscle and skin inflammation, free nerve endings of amyelinic fibres are devoted to the perception of pain release SP, which, together with other mediators (NO, PG, BKN, etc.), increases peripheral sensitization and initiates the onset of altered neuroplasticity. This has the potential to lead to chronic pain. In humans, axonal reflexes, characterized by vasodilatation (flare) surrounding the area of stimulated peripheral nerve fibres, take part in the neurogenic inflammation response via release of calcitonin-gene-related peptide (CGRP), ${ }^{[77,78]}$ the principal neurotransmitter released in inflammation. ${ }^{[79]}$

\subsubsection{In Vitro Studies and Animal Models}

In in vitro studies, BTX-A inhibited SP and ACh release from the trigeminal nerve terminals of the rabbit iris sphincter muscle, ${ }^{[80]}$ and in rat dorsal root

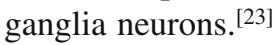

In a formalin pain model in the rat (subcutaneous formalin injection in the hindpaw), the antinociceptive effect of BTX-A pre-treatment without muscle weakness was demonstrated. ${ }^{[81]}$ The effect of a formalin injection has two phases: the nociceptive phase, which consists of immediate pain due to direct stimulation of chemoreceptors and polymodal nociceptors, and a second slowly developing pain, characterized by neurogenic inflammation and nociceptor central sensitization. In this study, BTX-A appeared to have no effect on the first phase but did inhibit the formalin-related spontaneous nociceptive effect in a dose-dependent fashion during the inflammatory second phase. ${ }^{[81]}$ The observed antinociceptive effect of BTX-A in the absence of muscle weakness was associated with inhibition of formalin-induced release of glutamate (and other neuropeptides SP and CGRP) from primary afferent terminals. $^{[81]}$

While only speculative, the results of these animal studies are indicative of possible parallel clinical utility in humans. These data suggest that BTX may be effective in the treatment of patients with chronic pain syndromes due to inhibition of neurogenic inflammation.

\subsubsection{In Humans}

It has been hypothesized that BTX effectiveness in peripheral neuropathies or in interstitial cystitis, where the antidromic barrage maintains a neuropathic painful state, could be attributed to the peripheral action of BTX to inhibit the release of neuropeptides activated by the antidromic pathway. ${ }^{[9]}$ Indeed, the clinical effectiveness of BTX in improvement of neurovascular disorders, including migraine and other headaches, ${ }^{[55-60]}$ chronic facial pain, ${ }^{[82,83]}$ trigeminal neuralgia ${ }^{[84]}$ and pain related to spinal cord pathology, ${ }^{[85]}$ has been described. Although the precise mechanism of the analgesic effect of BTX has not yet been defined, some aspects are now widely accepted. Firstly, BTX seems not to affect acute nociceptive pain related to $\mathrm{A} \delta$ and $\mathrm{C}$ fibre conduction, as shown by the failure of BTX-A to modify thermal or thermal-pain thresholds. ${ }^{[86,87]}$ However, reductions in cutaneous erythema in cholinergic urticaria, ${ }^{[82]}$ chronic facial pain $^{[88]}$ and Frey's syndrome ${ }^{[21]}$ demonstrated the role of BTX in regulation of vessel tone and permeability. Following these observations in humans, models were developed to investigate the pathogenesis of human chronic neuropathic pain by provoking peripheral 
a

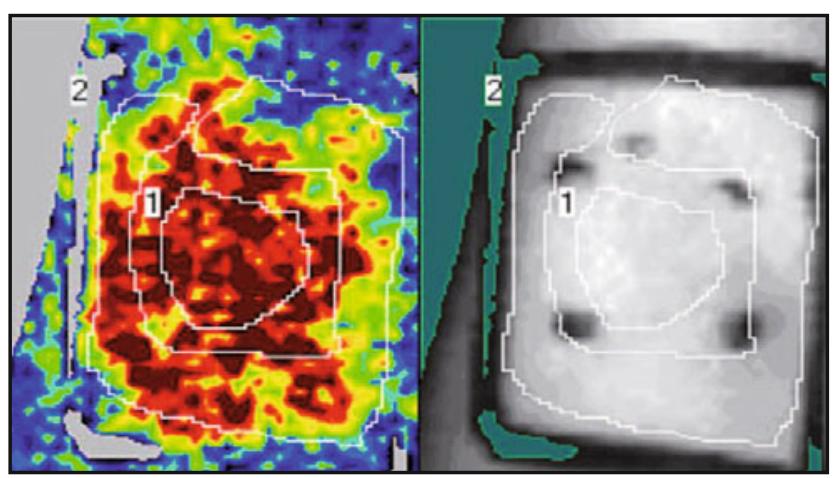

b

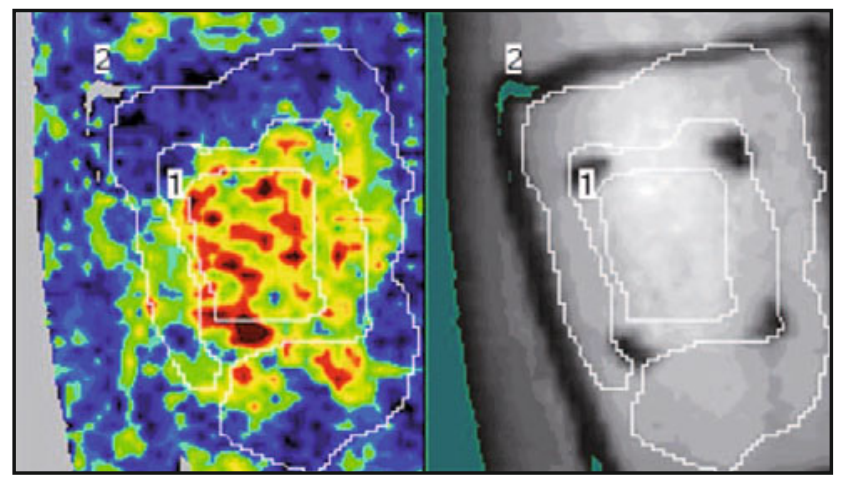

Fig. 4. Laser Doppler imaging (Perimed Inc., Järfälla, Sweden) showing examples of neurogenic flare induced by cutaneous capsaicin administration inside (a) saline- and (b) botulinum toxin (BTX)-pretreated areas. The rectangular treated areas (1) have been outlined; the capsaicin administration areas (2) have been demarcated by four points. A significant reduction in superficial blood flow was detected in the BTX-pretreated site.

nociceptor activation. Capsaicin, electrical stimulation or UVB irradiation ${ }^{[79,87,89-91]}$ are typically used to induce skin inflammation and hyperalgesia. The human pain models used allowed simultaneous study of the possible reduction of inflammatory aspects such as cutaneous flare induced by local axonal reflexes and the possible antihyperalgetic effect of these stimuli on spontaneous pain and on primary and secondary hyperalgesia. However, the clinical data obtained are inconsistent: some studies have shown a decrease in cutaneous vasodilatation, as detected by a reduction in flare area or by cutaneous flowmetry, with BTX treatment (figure 4), ${ }^{[79,89,91]}$ while others have not. ${ }^{[87,90]}$ In some studies, pain perception and hyperalgesia appeared not to be changed, ${ }^{[87,89,90]}$ while other studies showed a significant decrease. ${ }^{[79,91]}$

This lack of homogeneity among experimental data and the conflicting clinical data could be due to the complexity of mechanisms involved in the inflammatory process, as well as to the variation in experimental conditions used. For example, the range of different study types (an in vitro study of purified endopeptidasic fragment in a primary culture of embryonic rat dorsal root ganglia neurons ${ }^{[23]}$ compared with use of the entire molecule in vivo in human $\operatorname{skin}^{[87]}$, the size of cutaneous area treated, and the timing chosen by the different authors were very different. In addition, it is not clear from current data whether the decrease in flare area and the amount of pain perception are independent BTX 
effects. ${ }^{[1]}$ In any case, BTX appears to be able to inhibit local release of pain-inducing neuropeptides such as CGRP from both cholinergic terminals and free endplates, preventing local sensitization of nociceptors. A reduction in the peripheral nociceptive barrage would contribute to a reduction in central activation associated with chronic pain. ${ }^{[92]}$ An interesting possible mechanism for reduced pain and neurogenic vasodilatation, not yet entirely documented in humans, is the possibility that BTX could block exocytosis of SNARE-dependent TRPV1, a primary player in the perception of peripheral thermal and inflammatory pain, to the neuron surface. ${ }^{[93]}$

\subsection{BTX and Axonal Transport}

Once injected, BTX binds to the nerve endplate, where it blocks neurotransmission. Inside the cell, BTX separates into heavy and light chains. The light chain cleaves target proteins involved in exocytosis to prevent release of $\mathrm{ACh}$ and is then transferred antidromically along the nerve. In vitro studies with 125I-labelled BTX in the isolated cat gastrocnemius muscle demonstrated that BTX undergoes retrograde axonal transport and is distributed according to a disto-proximal gradient via the sciatic nerve to ganglions, dorsal roots and the ipsilateral medullary laminae of the spinal cord. ${ }^{[94]}$ These observations, dating back over 30 years, have been partially corrected by more recent studies demonstrating that BTX degradation fragments, and not the total BTX light chain, undergo retrograde transport, and there was no evidence of intact BTX accumulating in the spinal cord. ${ }^{[95]}$

\subsection{BTX and Inhibition of Spinal Ganglia}

Given the evidence for axonal transport of BTX, recent studies that have demonstrated the specific inhibitory activity of clostridial endopeptidasic fragments in vesicular exocytosis assume greater importance. In in vitro studies of dorsal root ganglia it was demonstrated that these fragments can inhibit the release of neurotransmitters from dorsal root ganglia $^{[13,23]}$ and, in particular, can inhibit SP release from nociceptive afferent ganglion neurons. ${ }^{[23]}$ This direct action of endopeptidases at the spinal level is due to the common utilization of the SNARE complex in ACh and SP synaptic release. As already described, inhibition of the production of ACh and SP derives from activation of the SNARE complex, which is blocked by endopeptidases. ${ }^{[96]}$

\subsection{BTX and Spinal Inhibition}

From a neurophysiological point of view, techniques such as modification of reciprocal inhibition, ${ }^{[7,35]}$ F-wave changes ${ }^{[97,98]}$ and the R2 component of the blink reflex ${ }^{[99]}$ have been used to obtain a general picture of the reduction in spinal excitability following intramuscular injection of BTX. The evidence for an effect of BTX on the central nervous system is inconsistent. In a study of 12 patients with upper limb dystonia, BTX improved upper limb dystonia and increased the abnormal second phase of reciprocal inhibition, suggesting an indirect effect on the spinal cord. ${ }^{[7]}$ This was probably through the action of BTX on the intrafusal neuromuscular junction in addition to its direct effect on the extrafusal neuromuscular junction. In another study in patients with lower limb spasticity, BTX significantly reduced spasticity and improved motor-evoked potentials (MEPs) induced by transcranial magnetic stimulation (TMS) 2 weeks after treatment in injected muscles only, suggesting a central alteration in responsiveness of spinal motor neurons to descending impulses from the corticospinal tracts. ${ }^{[97]}$ However, in 20 patients with post-stroke upper limb spasticity, BTX-A induced a decrease in muscle tone and an improvement in motility and functional status, without changes in inhibitory phases of reciprocal inhibition, suggesting that BTX-A efficacy is mainly due to peripheral effects. ${ }^{[35]}$ Also, a small study in 12 patients with blepharospasm demonstrated that BTX-A did not modify the excitability of brainstem interneurons that mediate the bilateral $\mathrm{R} 2$ response of the blink reflex. ${ }^{[99]}$

It is well known that BTX blocks Ia afferent signals from intrafusal muscle spindles (figure 2). ${ }^{[17]}$ Given that these afferents are involved in spinal hyperexcitability related to spasticity and chronic contraction, ${ }^{[100]}$ it is conceivable that BTX could reduce related muscle hyperactivity and pain. ${ }^{[27]}$ 
Furthermore, the spinal inhibition seen with BTX could explain the reduction in contraction and pain in wider muscular areas not directly related to the site of injection. ${ }^{[101]}$

\subsection{Suprasegmental Effects of BTX}

It has been postulated that chemical denervation with sustained paralysis, especially in muscles involved in complex motor functions, can induce reorganization of movement strategies at the central level (figure 1). The basis of this proposed mechanism of action was the observed change in motoneuronal firing in antagonistic muscles in the lateral rectus muscle fibres of the cat eye. ${ }^{[102]}$ Later, this outcome was confirmed in a study of longlatency reflexes ${ }^{[103]}$ and in studies in patients with dystonia where BTX-induced cortical modifications were investigated by positron emission tomography (PET). ${ }^{[104]}$ Modifications in the frontal association areas of the brain, in particular, were associated with increased activity in the parietal cortex and motor accessory areas, but BTX failed to normalize impaired activation of the primary motor cortex. ${ }^{[104]}$ Furthermore, two small studies in patients with dystonia ( $\mathrm{n}=12^{[105]}$ and $\mathrm{n}=15^{[106]}$ ) used TMS to demonstrate that BTX could transiently normalize the distorted primary motor cortex signals to dystonic muscles by reorganizing intracortical circuits in a similar fashion to that observed with prolonged immobilizations and anaesthetics.

Perfusion studies have demonstrated passage of BTX through the blood-brain barrier and its binding to cultured rat hippocampal neurons and astrocytes ${ }^{[107]}$ however, since only inactive fragments of BTX appear to be transported to the spinal cord via retrograde axonal transport, ${ }^{[95]}$ the modifications induced at suprasegmental level are most likely attributable to functional variations following reduction of Ia afferents and to paralysis-induced functional reorganization, rather than to direct BTX action on the suprasegmental centres themselves. ${ }^{[108]}$

\section{Efficacy, Technique and Therapeutic Dosages}

There are large discrepancies in the success rates reported with BTX use in pain management. In fact, figures vary between a surprising $80 \%$ in cervical dystonia $^{[109]}$ and an almost total inefficacy in percutaneous coeliac plexus block in the pain of chronic pancreatitis. ${ }^{[110]}$ Efficacy differences can be attributed to many factors: different disease pathologies, sites of injection, BTX dosages, use of BTX-A or BTX-B, and a lack of standard controls. These discrepancies, similar to those seen at the beginning of clinical development of BTX for movement disorders, ${ }^{\left[{ }^{[2]}\right]}$ have led to reservations about use of BTX in pain management. What is clear from current data is that BTX efficacy in pain management, as in the treatment of positive myofascial pain-related alterations of muscle tonus, is primarily dependent on the ability to deliver sufficient neurotoxin to the required site, despite local diffusion, without causing systemic effects. ${ }^{[101]}$ For a neuromuscular block aimed at achieving an analgesic effect, the injection method is based on the proposals made by the Gruppo Italiano per lo Studio dei Disturbi del Movimento della Società Italiana di Neurologia ${ }^{[111]}$ and by the Spasticity Study Group, ${ }^{[112]}$ standardized for the most common sites of myofascial pain.

In pain management, the mean doses of injected BTX are similar to those applied in movement disorders. ${ }^{[111]}$ Doses for the two serotypes commonly administered in humans are shown in table I. The literature indicates that $300 \mathrm{U}$ of Botox ${ }^{\circledR}$ (BTX-A; Allergan, Irvine, CA, USA) should be the maximum dose for pain management, not to be repeated within 12 weeks. ${ }^{[112]}$ However, use of BTX-A 400-450 U in neck muscles ${ }^{[113]}$ and up to $1000 \mathrm{U}$ in distal leg muscles has been reported. ${ }^{[114]}$ Expressing the potency of formulations of BTX-A in LD50 (dose that produces death in $50 \%$ of experimental animals) mouse units demonstrates that the different formulations are not equivalent dose-for-dose (table I). ${ }^{[115]}$ At present, two different strategies are being followed to establish the optimal therapeutic BTX-A dose for TrPs (Ipsen, data on file). The first strategy attempts to establish a minimum effective dose for a 


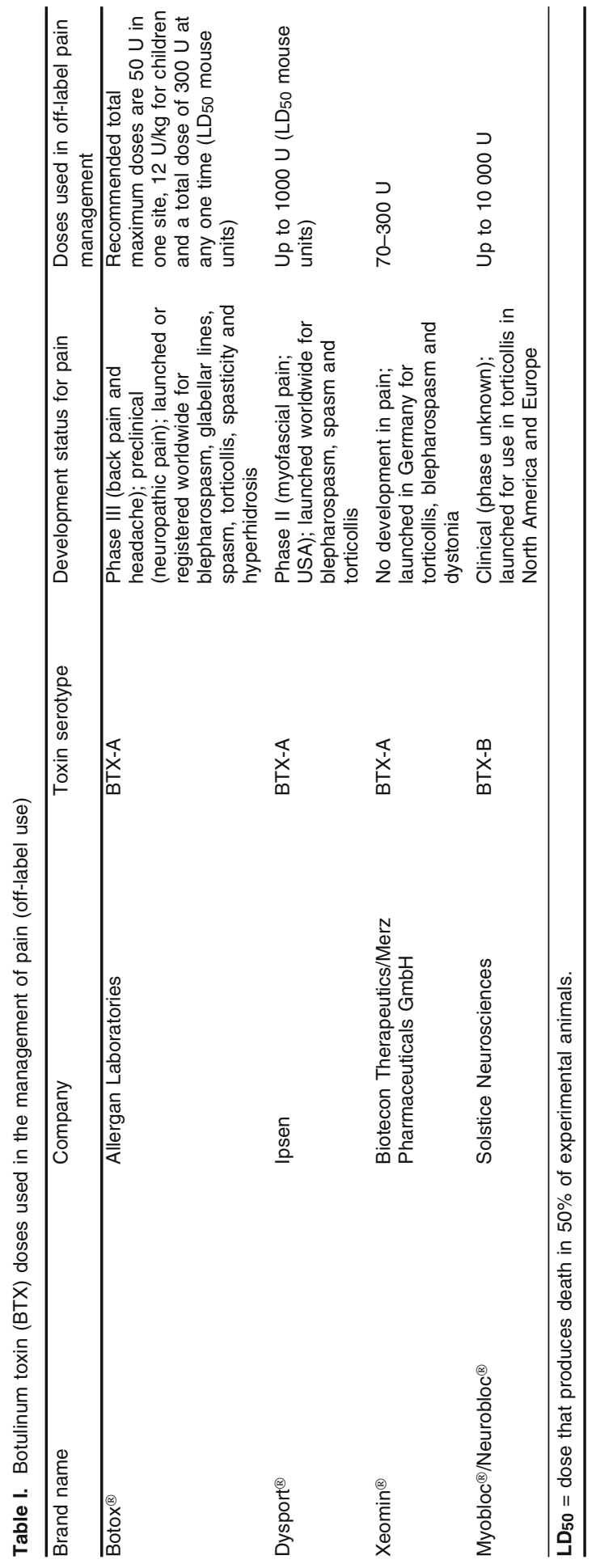

TrP regardless of the total number of TrPs (ensuring that the maximum dose limits are not exceeded). In the second strategy, the dose to be injected for each $\mathrm{TrP}$ is calculated by dividing the maximum dose by the number of TrPs identified by the Simons and Travell technique (figure 5 and figure 6$).{ }^{[116]}$ The TrP injection can be given as a single shot into the $\operatorname{TrP}$ or as multiple shots around and within the TrP. However, use of the multiple injection technique for BTX administration is controversial. ${ }^{[117]}$

The route and mode of BTX administration for targets such as the coeliac plexus or the stellate ganglion are more complex and difficult to establish. According to published clinical data, 1.5-2.5 $\mathrm{IU} / \mathrm{kg}$ of BTX-A in $15 \mathrm{~mL}$ of saline injected into the coeliac plexus had limited effect; the authors concluded that this dose was most probably insufficient. ${ }^{[110]}$

Repeated BTX administration is required to maintain the antinociceptive effect long term. A retrospective chart review of 60 patients showed that the average duration of effect of repeat injections of BTX was 16 weeks (range 12-24 weeks over four doses). ${ }^{[18]}$ The average dose was 265.7 IU (range 105-400 IU for doses one to four). In response to BTX-induced chemical denervation, new motoneurons are formed in the attempt to recover structuralfunctional connections with muscles. ${ }^{[119]}$ Therefore, in striated muscle, morphological and functional connections between motoneurons and muscle fibres are re-established after a few months, which explains the need for repeated BTX administration, although, to our knowledge, there are no studies showing direct correlation of the return of pain with structural-functional restoration of connections. Obviously, the administration schedule should consider the treatment efficacy and the presence of painful symptoms, as well as restoration of the motor-endplate connection. To date, although the long-term effects of repeated BTX injections are not known, there is no evidence that repeated BTX injections produce any serious adverse local or systemic effects and the beneficial effects are maintained for at least 5 years. ${ }^{[5]}$ 


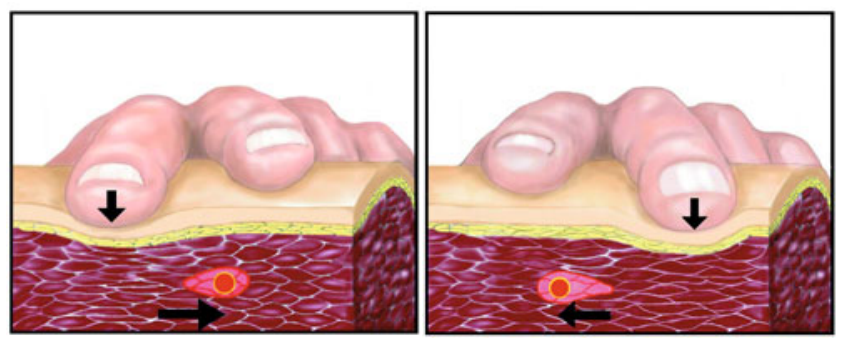

Fig. 5. llustration of trigger point (TrP) identification procedure. The TrP is detectable by means of manual palpation in which application of alternating pressure by the examiner's index and median fingers allows identification of the TrP within a taut band. Cutaneous, subcutaneous and muscle layers are shown.

Although functional recovery demonstrated in neuromuscular junctions in the somatic system has not been shown in sympathetic synapses of the autonomic system, clinical evidence of a reconnection, as in palmar hyperhidrosis after a variable period of several months, ${ }^{[20]}$ supports the hypothesis of a similar mechanism.

\section{Contraindications, Precautions and Critical Factors}

Although evidence of its efficacy in reducing pain has been reported, BTX is currently used 'off label' in pain management. Therefore, any treatment protocol must be approved by the relevant ethical committee and the patient informed-consent form must contain a clear and comprehensive explanation of the risk/benefit ratio as well as a statement concerning this unconventional use.

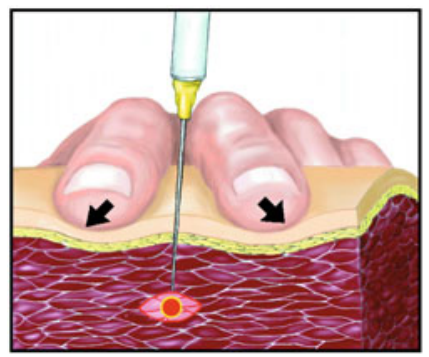

Fig. 6. Trigger point (TrP) injection technique. After its identification, the TrP is 'blocked' between the two fingers: note the simultaneous finger pressure on the muscle and the gentle stretch of the skin. If correctly performed, this technique allows for accurate injection of local anaesthetic or botulinum toxin into the TrP. When the needle reaches the TrP, an involuntary twitch or 'jump sign' is observed.
Some precautions and contraindications for BTX use in pain management taken from those normally considered in relation to its use in muscle tone disorders ${ }^{[111,112]}$ include (i) generalized hyposthenia (neuromuscular disorders, severe systemic pathologies and myopathies); (ii) atrophy in the target muscle; and (iii) concurrent therapy with aminoglycoside antibacterials. In addition, particular attention should be paid when BTX is injected into muscles with atypical functional characteristics, such as antigravity muscles and the anterior muscles of the neck, and in patients at high risk of iatrogenic effects, such as those with dysphagia. Moreover, BTX treatment of patients with concomitant somatoform disorders or conversion depressive diseases requires particular care.

The type of disorder is a critical factor influencing treatment. For painful conditions due to muscle contraction, selecting the correct dose of BTX to be injected is straightforward, whereas in neuropathic pain, as well as in pain due to inflammation or sympathetic system involvement where both the technique and the site of injection influence the correct therapeutic dose, selection of the correct dose is more problematical.

In pain management with BTX, as for any other innovative therapy, other general critical factors should be considered. These include concomitant treatments, the possibility that simultaneous and different pathophysiological mechanisms generating pain with similar clinical characteristics may coexist, as well as the presence of clinically similar painful conditions in pathologies with different aetiologies. 


\section{Conclusions}

Although muscular tone and movement disorders remain the most important therapeutic applications for BTX treatment and their use in these settings are supported by clinical data, studies show that BTX may also have application in modifying cholinergic control of the vascular system and modification of autonomic functions (such as sweating). In addition, BTX may also affect sensory intrafusal afferents involved in the cholinergic control of the $\gamma$-motoneuron loop implicated indirectly in nociceptive and antinociceptive systems. Furthermore, it seems that BTX can directly influence the release of substances inducing peripheral sensitization and can effect changes to the peripheral and central nervous systems.

BTX can also prevent or reduce pain development in neurogenic inflammation; it is transported along the peripheral nerve and directly influences SP production in dorsal ganglions, thus adding to inhibition of spinal hyperexcitability. Moreover, central cortical suprasegmental neural functions and fusal and antinociceptive control are affected by BTX. In specific circumstances, as in neuropathic pain or during the neurogenic inflammation phase, the binding characteristics of BTX appear to be increased, thus facilitating the interaction between BTX and other non-cholinergic nerve structures as nociceptive afferents.

Primarily, the therapeutic potential of BTX in pain management depends on whether the toxin can be delivered to the local target structure, cholinergic or otherwise. Current data suggest that, in chronic pain disorders where the primary goal is alteration of muscle tone, BTX should be administered at standard dosages (similar to those currently used in approved indications), while for conditions requiring an analgesic effect independent of muscle tone, the dosage remains to be defined.

\section{Acknowledgements}

No sources of funding were used to assist in the preparation of this review. The authors have no conflicts of interest that are directly relevant to the content of this review.

\section{References}

1. Irwin RW, Zuhosky JP, Sullivan WJ, et al. Industrial medicine and acute musculoskeletal rehabilitation: 4. Interventional procedures for work-related cervical spine conditions. Arch Phys Med Rehabil 2007; 88 (3 Suppl. 1): S18-21

2. Lang AM. Botulinum toxin type A therapy in chronic pain disorders. Arch Phys Med Rehabil 2003; 84 (3 Suppl. 1): S69-73; quiz S4-5

3. Lim EC, Seet RC. Botulinum toxin, quo vadis? Med Hypotheses 2007; 69 (4): 718-23

4. Singer BJ, Silbert PL, Dunne JW, et al. An open label pilot investigation of the efficacy of botulinum toxin type A [Dysport] injection in the rehabilitation of chronic anterior knee pain. Disabil Rehabil 2006; 28 (11): 707-13

5. Jankovic J, Schwartz K, Donovan DT. Botulinum toxin treatment in cervical dystonia, spasmodic dystonia, other focal dystonias and hemifacial spasm. J Neurol Neurosurg Psychiatry 1990; 53: 633-9

6. Tsui JK, Eisen A, Stoessl AJ, et al. Double-blind study of botulinum toxin in spasmodic torticollis. Lancet 1986; II (8501): 245-7

7. Priori A, Berardelli A, Mercuri B, et al. Physiological effects produced by botulinum toxin treatment of upper limb dystonia: changes in reciprocal inhibition between forearm muscles. Brain 1995; 118 (Pt 3): 801-7

8. Newman NJ, Lambert SR. Botulinum toxin treatment of supranuclear ocular motility disorders. Neurology 1992; 42 (7): 1391-3

9. Argoff CE. A focused review on the use of botulinum toxins for neuropathic pain. Clin J Pain 2002; 18 (6 Suppl.): S177-81

10. Arezzo JC. Possible mechanisms for the effects of botulinum toxin on pain. Clin J Pain 2002; 18 (6 Suppl.): S125-32

11. Greene P, Kang U, Fahn S, et al. Double-blind, placebo-controlled trial of botulinum toxin injections for the treatment of spasmodic torticollis. Neurology 1990; 40 (8): 1213-8

12. Naumann M, Yakovleff A, Durif F. A randomized, doublemasked, crossover comparison of the efficacy and safety of botulinum toxin type A produced from the original bulk toxin source and current bulk toxin source for the treatment of cervical dystonia. J Neurol 2002; 249 (1): 57-63

13. Duggan MJ, Quinn CP, Chaddock JA, et al. Inhibition of release of neurotransmitters from rat dorsal root ganglia by a novel conjugate of a Clostridium botulinum toxin A endopeptidase fragment and Erythrina cristagalli lectin. J Biol Chem 2002; 277 (38): 34846-52

14. Turton K, Chaddock JA, Acharya KR. Botulinum and tetanus neurotoxins: structure, function and therapeutic utility. Trends Biochem Sci 2002; 27 (11): 552-8

15. Brin MF, Swope DM, O'Brain C, et al. Botox for migraine: double-blind, placebo-controlled region-specific evaluation. Cephalalgia 2000; 20: 421-2

16. Gobel H, Heinze A, Heinze-Kuhn K, et al. Botulinum toxin A in the treatment of headache syndromes and pericranial pain syndromes. Pain 2001; 91 (3): 195-9

17. Rosales RL, Arimura K, Takenaga S, et al. Extrafusal and intrafusal muscle effects in experimental botulinum toxin-A injection. Muscle Nerve 1996; 19 (4): 488-96

18. Sung YJ, Ambron RT. Pathways that elicit long-term changes in gene expression in nociceptive neurons following nerve injury: contributions to neuropathic pain. Neurol Res 2004; 26 (2): $195-203$ 
19. Brisinda G, Bentivoglio AR, Maria G, et al. Treatment with botulinum neurotoxin of gastrointestinal smooth muscles and sphincters spasms. Mov Disord 2004; 19 Suppl. 8: S146-56

20. Collin J, Whatling P. Treating hyperhidrosis: surgery and botulinum toxin are treatments of choice in severe cases. BMJ 2000; 320 (7244): 1221-2

21. Tugnoli V, Marchese Ragona R, Eleopra R, et al. The role of gustatory flushing in Frey's syndrome and its treatment with botulinum toxin type A. Clin Auton Res 2002; 12 (3): 174-8

22. Eleopra R, Tugnoli V, Quatrale R, et al. Different types of botulinum toxin in humans. Mov Disord 2004; 19 Suppl. 8: S53-9

23. Welch MJ, Purkiss JR, Foster KA. Sensitivity of embryonic rat dorsal root ganglia neurons to Clostridium botulinum neurotoxins. Toxicon 2000; 38 (2): 245-58

24. Chaddock JA, Purkiss JR, Friis LM, et al. Inhibition of vesicular secretion in both neuronal and nonneuronal cells by a retargeted endopeptidase derivative of Clostridium botulinum neurotoxin type A. Infect Immun 2000; 68 (5): 2587-93

25. Kamanli A, Kaya A, Ardicoglu O, et al. Comparison of lidocaine injection, botulinum toxin injection, and dry needling to trigger points in myofascial pain syndrome. Rheumatol Int 2005; 25 (8): 604-11

26. Graboski CL, Gray DS, Burnham RS. Botulinum toxin A versus bupivacaine trigger point injections for the treatment of myofascial pain syndrome: a randomised double blind crossover study. Pain 2005; 118 (1-2): 170-5

27. Mense S. Neurobiological basis for the use of botulinum toxin in pain therapy. J Neurol 2004; 251 Suppl. 1: I1-7

28. Sheean G. Botulinum toxin for the treatment of musculoskeletal pain and spasm. Curr Pain Headache Rep 2002; 6 (6): 460-9

29. Meissner T. How botulinum toxin enriches orthopedics: toxin against contractures and pain [in German]. MMW Fortschr Med 2005; 147 (29-30): 10, 12

30. Silberstein N. More than a cosmetic fix: combined with physical therapy, botulinum toxin type A can help provide relief for chronic muscle pain. Rehab Manag 2007; 20 (1): 44-6

31. Cheshire WP, Abashian SW, Mann JD. Botulinum toxin in the treatment of myofascial pain syndrome. Pain 1994; 59 (1): 65-9

32. De Andres J, Cerda-Olmedo G, Valia JC, et al. Use of botulinum toxin in the treatment of chronic myofascial pain. Clin J Pain 2003; 19 (4): 269-75

33. Qerama E, Fuglsang-Frederiksen A, Kasch H, et al. A doubleblind, controlled study of botulinum toxin A in chronic myofascial pain. Neurology 2006; 67 (2): 241-5

34. Wissel J, Muller J, Dressnandt J, et al. Management of spasticity associated pain with botulinum toxin A. J Pain Symptom Manage 2000; 20 (1): 44-9

35. Girlanda P, Quartarone A, Sinicropi S, et al. Botulinum toxin in upper limb spasticity: study of reciprocal inhibition between forearm muscles. Neuroreport 1997; 8 (14): 3039-44

36. Miles MP, Clarkson PM. Exercise induced muscle pain, soreness and cramps. J Sports Med Phys Fitness 1994; 34 (3) 203-16

37. Mense $S$. The pathogenesis of muscle pain. Curr Pain Headache Rep 2003; 7 (6): 419-25

38. Simms RW. Fibromyalgia is not a muscle disorder. Am J Med Sci 1998; 315 (6): 346-50

39. Boureau F, Delorme T, Doubrere JF. Mechanisms of myofascial pain [in French]. Rev Neurol (Paris) 2000; 156 Suppl. 4: 4S10-4
40. Acquadro MA, Borodic GE. Treatment of myofascial pain with botulinum A toxin. Anesthesiology 1994; 80 (3): 705-6

41. Criscuolo CM. Interventional approaches to the management of myofascial pain syndrome. Curr Pain Headache Rep 2001; 5 (5): 407-11

42. Diaz JH, Gould 3rd HJ. Management of post-thoracotomy pseudoangina and myofascial pain with botulinum toxin. Anesthesiology 1999; 91 (3): 877-9

43. Porta M. A comparative trial of botulinum toxin type A and methylprednisolone for the treatment of myofascial pain syndrome and pain from chronic muscle spasm. Pain 2000; 85 (1-2): 101-5

44. Wheeler AH, Goolkasian P, Gretz SS. A randomized, doubleblind, prospective pilot study of botulinum toxin injection for refractory, unilateral, cervicothoracic, paraspinal, myofascial pain syndrome. Spine 1998; 23 (15): 1662-6; discussion 7

45. Travell JG, Simons DG. Myofascial pain and dysfunction: the trigger point manual. Baltimore, London: Williams \& Wilkins, 1983

46. Simons DG. Clinical and etiological update of myofascial pain from trigger points. J Musculoskeletal Pain 1996; 4: 93-121

47. Khalsa PS. Biomechanics of musculoskeletal pain: dynamics of the neuromatrix. J Electromyogr Kinesiol 2004; 14 (1): 109-20

48. Barbagli P, Bollettin R, Ceccherelli F. Acupuncture (dry needle) versus neural therapy (local anesthesia) in the treatment of benign back pain: immediate and long-term results. Minerva Med 2003; 94 (4 Suppl. 1): 17-25

49. Speed CA. Injection therapies for soft-tissue disorders. Best Pract Res Clin Rheumatol 2003; 17 (1): 167-81

50. Richards BA, Jensen. A double-blind, controlled study of botulinum toxin A in chronic myofascial pain [letter]. Neurology 2007; 68 (12): 964

51. Gobel H, Heinze A, Reichel G, et al. Efficacy and safety of a single botulinum type A toxin complex treatment (Dysport) for the relief of upper back myofascial pain syndrome: results from a randomized double-blind placebo-controlled multicentre study. Pain 2006; 125 (1-2): 82-8

52. Ho KY, Tan KH. Botulinum toxin A for myofascial trigger point injection: a qualitative systematic review. Eur J Pain 2007; 11 (5): 519-27

53. Juan FJ. Use of botulinum toxin-A for musculoskeletal pain in patients with whiplash associated disorders. BMC Musculoskelet Disord 2004; E5: 5

54. Kelm S, Gerats G, Chalkiadaki A, et al. Reduction of pain and muscle spasms by botulinum toxin A [in German]. Nervenarzt 2001; 72 (4): 302-6

55. Dodick DW, Mauskop A, Elkind AH, et al. Botulinum toxin type A for the prophylaxis of chronic daily headache: subgroup analysis of patients not receiving other prophylactic medications: a randomized double-blind, placebo-controlled study. Headache 2005; 45 (4): 315-24

56. Silberstein SD. Review of botulinum toxin type A and its clinical applications in migraine headache. Expert Opin Pharmacother 2001; 2 (10): 1649-54

57. Troost BT. Botulinum toxin type A (Botox) in the treatment of migraine and other headaches. Expert Rev Neurother 2004; 4 (1): $27-31$

58. Vo AH, Satori R, Jabbari B, et al. Botulinum toxin type-A in the prevention of migraine: a double-blind controlled trial. Aviat Space Environ Med 2007; 78 (5 Suppl.): B113-8

59. Gwynn MW, Baker T, English J. Double-blind, placebo-controlled study of botulinum toxin B for the treatment of chronic 
headache [plus poster]. Neurology 2003; 60 Suppl. 1: 322 [P04 149]

60. Lake III AE, Saper JR. Botulinum toxin type B for migraine prophylaxis: a 4-month open-label prospective outcome study [plus poster]. Neurology 2003; 60 Suppl. 1: 322 [P04 150]

61. Turk DC, Flor H. Primary fibromyalgia is greater than tender points: toward a multiaxial taxonomy. J Rheumatol Suppl 1989; 19: 80-6

62. Wolfe F, Smythe HA, Yunus MB, et al. The American College of Rheumatology 1990 Criteria for the Classification of Fibromyalgia. Report of the Multicenter Criteria Committee. Arthritis Rheum 1990; 33 (2): 160-72

63. Lautenbacher S, Rollman GB. Possible deficiencies of pain modulation in fibromyalgia. Clin J Pain 1997; 13 (3): 189-96

64. Eisinger J, Plantamura A, Ayavou T. Glycolysis abnormalities in fibromyalgia. J Am Coll Nutr 1994; 13 (2): 144-8

65. Park JH, Niermann KJ, Olsen N. Evidence for metabolic abnormalities in the muscles of patients with fibromyalgia. Curr Rheumatol Rep 2000; 2 (2): 131-40

66. Granges G, Littlejohn G. Pressure pain threshold in pain-free subjects, in patients with chronic regional pain syndromes, and in patients with fibromyalgia syndrome. Arthritis Rheum 1993; 36 (5): 642-6

67. Morris V, Cruwys S, Kidd B. Increased capsaicin-induced secondary hyperalgesia as a marker of abnormal sensory activity in patients with fibromyalgia. Neurosci Lett 1998; 250 (3): 205-7

68. Sorensen J, Graven-Nielsen T, Henriksson KG, et al. Hyperexcitability in fibromyalgia. J Rheumatol 1998; 25 (1): 152-5

69. Gracely RH, Petzke F, Wolf JM, et al. Functional magnetic resonance imaging evidence of augmented pain processing in fibromyalgia. Arthritis Rheum 2002; 46 (5): 1333-43

70. Staud R, Robinson ME, Vierck Jr CJ, et al. Diffuse noxious inhibitory controls (DNIC) attenuate temporal summation of second pain in normal males but not in normal females or fibromyalgia patients. Pain 2003; 101 (1-2): 167-74

71. Bromage PR, Melzack R. Phantom limbs and the body schema. Can Anaesth Soc J 1974; 21 (3): 267-74

72. Wall PD. Introduction to the edition after this one. In Wall PD, Melzack R, editors. Textbook of pain. 3rd ed. Edinburgh: Churchill Livingstone, 1994: 1-7

73. Asherson RA, Pascoe L. The use of botulinum toxin-A in the treatment of patients with fibromyalgia [letter of comment]. J Rheumatol 2001; 28 (7): 1740

74. Ferreira JJ, Couto M, Costa J, et al. Botulinum toxin for the treatment of pain syndromes. Acta Reumatol Port 2006; 31 (1): 49-62

75. Paulson GW, Gill W. Botulinum toxin is unsatisfactory therapy for fibromyalgia [letter]. Mov Disord 1996; 11 (4): 459

76. Benecke R, Dressler D, Kunesch E, et al. Use of botulinum toxin in the treatment of muscle pain [in German]. Schmerz 2003; 17 (6): $450-8$

77. Kilo S, Harding-Rose C, Hargreaves KM, et al. Peripheral CGRP release as a marker for neurogenic inflammation: a model system for the study of neuropeptide secretion in rat paw skin. Pain 1997; 73 (2): 201-7

78. Pedersen-Bjergaard U, Nielsen LB, Jensen K, et al. Calcitonin gene-related peptide, neurokinin A and substance P: effects on nociception and neurogenic inflammation in human skin and temporal muscle. Peptides 1991; 12 (2): 333-7

79. Gazerani P, Staahl C, Drewes AM, et al. The effects of botulinum toxin type A on capsaicin-evoked pain, flare, and secon- dary hyperalgesia in an experimental human model of trigeminal sensitization. Pain 2006; 122 (3): 315-25

80. Ishikawa H, Mitsui Y, Yoshitomi T, et al. Presynaptic effects of botulinum toxin type A on the neuronally evoked response of albino and pigmented rabbit iris sphincter and dilator muscles. Jpn J Ophthalmol 2000; 44 (2): 106-9

81. Cui M, Khanijou S, Rubino J, et al. Subcutaneous administration of botulinum toxin A reduces formalin-induced pain. Pain 2004; 107 (1-2): 125-33

82. Borodic GE, Acquadro M, Johnson EA. Botulinum toxin therapy for pain and inflammatory disorders: mechanisms and therapeutic effects. Expert Opin Investig Drugs 2001; 10 (8): 1531-44

83. Borodic GE, Acquadro MA. The use of botulinum toxin for the treatment of chronic facial pain. J Pain 2002; 3 (1): 21-7

84. Allam N, Brasil-Neto JP, Brown G, et al. Injections of botulinum toxin type A produce pain alleviation in intractable trigeminal neuralgia. Clin J Pain 2005; 21 (2): 182-4

85. Jabbari B, Maher N, Difazio MP. Botulinum toxin A improved burning pain and allodynia in two patients with spinal cord pathology. Pain Med 2003; 4 (2): 206-10

86. Blersch W, Schulte-Mattler WJ, Przywara S, et al. Botulinum toxin A and cutaneous nociception in humans: a prospective, double-blind, placebo-controlled, randomized study. J Neurol Sci 2002; 205 (1): 59-63

87. Voller B, Sycha T, Gustorff B, et al. A randomized, doubleblind, placebo controlled study on analgesic effects of botulinum toxin A. Neurology 2003; 61 (7): 940-4

88. Junghans $\mathrm{K}$, Rohrbach S, Ellies $\mathrm{M}$, et al. Improvement of chronic facial pain and facial dyskinesia with the help of botulinum toxin application. Head Face Med 2007; E3: 32

89. Kramer HH, Angerer C, Erbguth F, et al. Botulinum toxin A reduces neurogenic flare but has almost no effect on pain and hyperalgesia in human skin. J Neurol 2003; 250 (2): 188-93

90. Sycha T, Samal D, Chizh B, et al. A lack of antinociceptive or antiinflammatory effect of botulinum toxin A in an inflammatory human pain model. Anesth Analg 2006; 102 (2): 509-16

91. Tugnoli V, Capone JG, Eleopra R, et al. Botulinum toxin type A reduces capsaicin-evoked pain and neurogenic vasodilatation in human skin. Pain 2007; 130 (1-2): 76-83

92. Aoki KR. Pharmacology and immunology of botulinum toxin serotypes. J Neurol 2001; 248 Suppl. 1: 3-10

93. Morenilla-Palao C, Planells-Cases R, Garcia-Sanz N, et al. Regulated exocytosis contributes to protein kinase $\mathrm{C}$ potentiation of vanilloid receptor activity. J Biol Chem 2004; 279 (24): 25665-72

94. Wiegand HH, Benecke R, Erdmann G. On the neural ascent of 125 I-labelled botulinum toxin A into the spinal cord and on the action of unlabelled botulinum toxin $\mathrm{A}$ in the spinal cord and in the nictitating membrane. Acad Sci Arts Bosnia Herzegovina 1976; 29: 91-8

95. Aoki R. The development of Botox, its history and pharmacology. Pain Digest 1998; 8: 337-41

96. Chaddock JA, Purkiss JR, Alexander FC, et al. Retargeted clostridial endopeptidases: inhibition of nociceptive neurotransmitter release in vitro, and antinociceptive activity in in vivo models of pain. Mov Disord 2004; 19 Suppl. 8: S42-7

97. Pauri F, Boffa L, Cassetta E, et al. Botulinum toxin type-A treatment in spastic paraparesis: a neurophysiological study. J Neurol Sci 2000; 181 (1-2): 89-97

98. Wohlfarth K, Schubert M, Rothe B, et al. Remote F-wave changes after local botulinum toxin application. Clin Neurophysiol 2001; 112 (4): 636-40 
99. Grandas F, Traba A, Alonso F, et al. Blink reflex recovery cycle in patients with blepharospasm unilaterally treated with botulinum toxin. Clin Neuropharmacol 1998; 21 (5): 307-11

100. Burke D, Lance JW. Studies of the reflex effects of primary and secondary spindle endings in spasticity. In: Desmedt JE, editor. New developments in electromyography and clinical neurophysiology. Basel: Kager AG, 1973: 475-9

101. Shaari CM, Sanders I. Quantifying how location and dose of botulinum toxin injections affect muscle paralysis. Muscle Nerve 1993; 16 (9): 964-9

102. Moreno-Lopez B, Pastor AM, de la Cruz RR, et al. Dosedependent, central effects of botulinum neurotoxin type A: a pilot study in the alert behaving cat. Neurology 1997; 48 (2): 456-64

103. Naumann M, Reiners K. Long-latency reflexes of hand muscles in idiopathic focal dystonia and their modification by botulinum toxin. Brain 1997; 120 (Pt 3): 409-16

104. Ceballos-Baumann AO, Sheean G, Passingham RE, et al. Botulinum toxin does not reverse the cortical dysfunction associated with writer's cramp: a PET study. Brain 1997; 120 (Pt 4): 571-82

105. Gilio F, Curra A, Lorenzano C, et al. Effects of botulinum toxin type A on intracortical inhibition in patients with dystonia. Ann Neurol 2000; 48 (1): 20-6

106. Byrnes ML, Thickbroom GW, Wilson SA, et al. The corticomotor representation of upper limb muscles in writer's cramp and changes following botulinum toxin injection. Brain 1998; 121 (Pt 5): 977-88

107. Verderio $\mathrm{C}$, Coco $\mathrm{S}$, Rossetto $\mathrm{O}$, et al. Internalization and proteolytic action of botulinum toxins in CNS neurons and astrocytes. J Neurochem 1999; 73 (1): 372-9

108. Dressler D, Saberi FA, Barbosa ER. Botulinum toxin: mechanisms of action. Arq Neuropsiquiatr 2005; 63 (1): 180-5

109. Lew MF, Adornato BT, Duane DD, et al. Botulinum toxin type B: a double-blind, placebo-controlled, safety and efficacy study in cervical dystonia. Neurology 1997; 49 (3): 701-7

110. Sherman S, Kopecky KK, Brashear A, et al. Percutaneous celiac plexus block with botulinum toxin A did not help the pain of chronic pancreatitis. J Clin Gastroenterol 1995; 20 (4): 343-4

111. Berardelli A, Abbruzzese G, Bertolasi L, et al. Guidelines for the therapeutic use of botulinum toxin in movement disorders.
Italian Study Group for Movement Disorders, Italian Society of Neurology. Ital J Neurol Sci 1997; 18 (5): 261-9

112. Brin MF. Dosing, administration, and a treatment algorithm for use of botulinum toxin A for adult-onset spasticity. Spasticity Study Group. Muscle Nerve 1997; 6 Suppl.: S208-20

113. Albanese A, Colosimo C, Carretta D, et al. Botulinum toxin as a treatment for blepharospasm, spasmodic torticollis and hemifacial spasm. Eur Neurol 1992; 32 (2): 112-7

114. Dengler R, Neyer U, Wohlfarth K, et al. Local botulinum toxin in the treatment of spastic drop foot. J Neurol 1992; 239 (7): 375-8

115. Sampairo C, Ferreia JJ, Simes F, et al. DYSBOT: a single-blind, randomized parallel study to determine whether any differences can be detected in the efficacy and tolerability of two formulations of botulinum toxin type A - Dysport and Botox assuming a ratio of 4:1. Movement Disorders 1997; 12: 1013-8

116. Simons DG, Travell JG. Myofascial origins of low back pain: 1 . Principles of diagnosis and treatment. Postgrad Med 1983; 73 (2): 66, 8-70, 3 passim

117. Bonica JJ. Local anaesthesia and regional blocks. In: Wall PD, Melzack R, editors. Textbook of pain. Edinburgh: Churchill Livingstone, 1984: 541-57

118. Magar R, Marchetti A, Lau H, et al. Botulinum toxin type A (BOTOX) for cervical dystonia: duration of clinical effect [abstract no. 754]. Movement Disorders 2000; 15 Suppl. 3: 151-2 (plus poster)

119. dePaiva A, Meunier FA, Molgo J, et al. Functional repair of motor endplates after botulinum neurotoxin type A poisoning: biphasic switch of synaptic activity between nerve sprouting and their parent terminals. Proc Natl Acad Sci U S A 1999; 96 (6): $3200-5$

Correspondence: Dr Roberto Casale, Department of Clinical Neurophysiology and Pain Rehabilitation Unit, Foundation Salvatore Maugeri, IRCCS, Scientific Institute of Montescano, Via per Montescano, 27040 Montescano (PV), Italy. 